Supplement of Atmos. Chem. Phys., 22, 625-639, 2022

https://doi.org/10.5194/acp-22-625-2022-supplement

(C) Author(s) 2022. CC BY 4.0 License.

(c) (1)

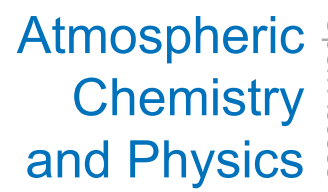

Supplement of

\title{
Prediction of secondary organic aerosol from the multiphase reaction of gasoline vapor by using volatility-reactivity base lumping
}

Sanghee Han and Myoseon Jang

Correspondence to: Myoseon Jang (mjang@ufl.edu)

The copyright of individual parts of the supplement might differ from the article licence. 


\section{Section S1. Gasoline fuel composition and its application to Carbon Bond 6}

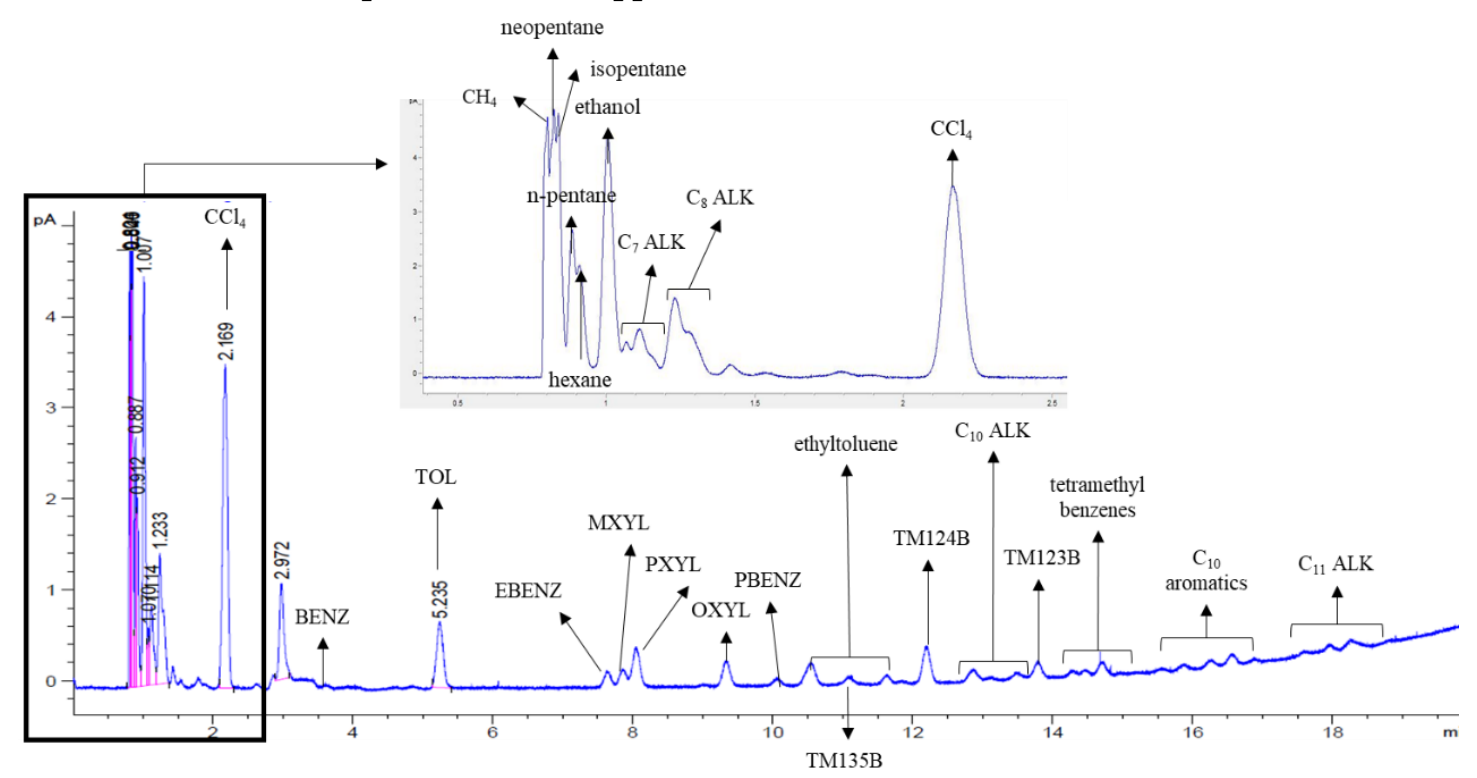

Figure S1. The GC-FID chromatogram of gasoline fuel.

Figure S1 illustrates the GC-FID chromatogram of gasoline vapor. To separate GC peaks, the oven temperature was held at $35^{\circ} \mathrm{C}$ for 3 minutes and increased to $120^{\circ} \mathrm{C}$ at $5{ }^{\circ} \mathrm{C} \mathrm{min}^{-1}$. The aromatic $\mathrm{HC}$ fraction to total hydrocarbons was about 30\%. The reaction rate constants and gas mechanisms used in CB6r3 are as follows.

Table S1. Reactions of aromatic HCs of this study with an $\mathrm{OH}$ radical and their rate constants

\begin{tabular}{|c|c|c|c|}
\hline Aromatic HC & Reaction mechanisms & Rate constants & References $^{\text {a) }}$ \\
\hline benzene & $\begin{array}{l}\mathrm{BENZENE}+\mathrm{OH} \rightarrow 0.530 * \mathrm{CRES}+0.352 * \mathrm{BZO} 2+0.352 * \mathrm{RO} 2+ \\
0.118 * \mathrm{OPEN}+0.118 * \mathrm{OH}+0.530 * \mathrm{HO} 2+\mathrm{BENZRO} 2\end{array}$ & $2.30 \times 10^{-12} \mathrm{e}^{-190.00 / \mathrm{T}}$ & CB6r3 $^{1}$ \\
\hline toluene & $\begin{array}{l}\mathrm{TOL}+\mathrm{OH} \rightarrow 0.180 * \mathrm{CRES}+0.650 * \mathrm{TO} 2+0.720 * \mathrm{RO} 2+0.100 * \mathrm{OPEN}+ \\
0.100 * \mathrm{OH}+0.070 * \mathrm{XO} 2 \mathrm{H}+0.180 * \mathrm{HO} 2+\mathrm{TOLRO} 2\end{array}$ & $1.80 \times 10^{-12} \mathrm{e}^{340.00 / \mathrm{T}}$ & CB6r $^{1}$ \\
\hline ethylbenzene & $\begin{array}{l}\mathrm{EBENZ}+\mathrm{OH} \rightarrow 0.180 * \mathrm{CRES}+0.650 * \mathrm{TO} 2+0.720 * \mathrm{RO} 2+ \\
0.100 * \mathrm{OPEN}+0.100 * \mathrm{OH}+0.070 * \mathrm{XO} 2 \mathrm{H}+0.180 * \mathrm{HO} 2+\mathrm{TOLRO} 2 \\
\mathrm{PAR}+\mathrm{OH} \rightarrow \mathrm{XPAR}\end{array}$ & $\begin{array}{l}7.00 \times 10^{-12} \\
8.1 \times 10^{-13}\end{array}$ & $\begin{array}{l}\text { MCM v3.3.1 } \\
\text { CB6r }^{1}\end{array}$ \\
\hline propylbenzene & $\begin{array}{l}\mathrm{PBENZ}+\mathrm{OH} \rightarrow 0.180 * \mathrm{CRES}+0.650 * \mathrm{TO} 2+0.720 * \mathrm{RO} 2+ \\
0.100 * \mathrm{OPEN}+0.100 * \mathrm{OH}+0.070 * \mathrm{XO} 2 \mathrm{H}+0.180 * \mathrm{HO} 2+\mathrm{TOLRO} 2 \\
2 \mathrm{PAR}+2 \mathrm{OH} \rightarrow 2 \mathrm{XPAR}\end{array}$ & $\begin{array}{l}5.8 \times 10^{-12} \\
8.1 \times 10^{-13}\end{array}$ & $\begin{array}{l}\text { MCM v3.3.12 } \\
{\text { CB6r } 3^{1}}^{12}\end{array}$ \\
\hline o-xylene & $\begin{array}{l}\mathrm{OXYL}+\mathrm{OH} \rightarrow 0.155 * \mathrm{CRES}+0.544 * \mathrm{XLO} 2+0.602 * \mathrm{RO} 2+ \\
0.244 * \mathrm{XOPN}+0.244 * \mathrm{OH}+0.058 * \mathrm{XO} 2 \mathrm{H}+0.155 * \mathrm{HO} 2+\mathrm{XYLRO} 2\end{array}$ & $1.36 \times 10^{-11}$ & $\mathrm{MCM}$ v3.3.12 \\
\hline m-xylene & $\begin{array}{l}\mathrm{MXYL}+\mathrm{OH} \rightarrow 0.155 * \mathrm{CRES}+0.544 * \mathrm{XLO} 2+0.602 * \mathrm{RO} 2+ \\
0.244 * \mathrm{XOPN}+0.244 * \mathrm{OH}+0.058 * \mathrm{XO} 2 \mathrm{H}+0.155 * \mathrm{HO} 2+\mathrm{XYLRO} 2\end{array}$ & $2.31 \times 10^{-11}$ & MCM v3.3.1 \\
\hline p-xylene & $\begin{array}{l}\mathrm{PXYL}+\mathrm{OH} \rightarrow 0.155 * \mathrm{CRES}+0.544 * \mathrm{XLO} 2+0.602 * \mathrm{RO} 2+ \\
0.244 * \mathrm{XOPN}+0.244 * \mathrm{OH}+0.058 * \mathrm{XO} 2 \mathrm{H}+0.155 * \mathrm{HO} 2+\mathrm{XYLRO} 2\end{array}$ & $1.43 \times 10^{-11}$ & MCM v3.3.1 \\
\hline TM123B & $\begin{array}{l}\mathrm{TM} 123 \mathrm{~B}+\mathrm{OH} \rightarrow 0.155 * \mathrm{CRES}+0.544 * \mathrm{XLO} 2+0.602 * \mathrm{RO} 2+ \\
0.244 * \mathrm{XOPN}+0.244 * \mathrm{OH}+0.058 * \mathrm{XO} 2 \mathrm{H}+0.155 * \mathrm{HO} 2+\mathrm{XYLRO} 2 \\
\mathrm{PAR}+\mathrm{OH} \rightarrow \mathrm{XPAR}\end{array}$ & $\begin{array}{l}3.27 \times 10^{-11} \\
8.1 \times 10^{-13}\end{array}$ & $\begin{array}{l}\text { MCM v3.3.12 } \\
\text { CB6r3 }\end{array}$ \\
\hline TM124B & $\begin{array}{l}\mathrm{TM} 124 \mathrm{~B}+\mathrm{OH} \rightarrow 0.155 * \mathrm{CRES}+0.544 * \mathrm{XLO} 2+0.602 * \mathrm{RO} 2+ \\
0.244 * \mathrm{XOPN}+0.244 * \mathrm{OH}+0.058 * \mathrm{XO} 2 \mathrm{H}+0.155 * \mathrm{HO} 2+\mathrm{XYLRO} 2 \\
\mathrm{PAR}+\mathrm{OH} \rightarrow \mathrm{XPAR}\end{array}$ & $\begin{array}{l}3.25 \times 10^{-11} \\
8.1 \times 10^{-13}\end{array}$ & $\begin{array}{l}\text { MCM v3.3.12 } \\
\text { CB6r3 }^{1}\end{array}$ \\
\hline TM135B & $\begin{array}{l}\mathrm{TM} 125 \mathrm{~B}+\mathrm{OH} \rightarrow 0.155 * \mathrm{CRES}+0.544 * \mathrm{XLO} 2+0.602 * \mathrm{RO} 2+ \\
0.244 * \mathrm{XOPN}+0.244 * \mathrm{OH}+0.058 * \mathrm{XO} 2 \mathrm{H}+0.155 * \mathrm{HO} 2+\mathrm{XYLRO} 2 \\
\mathrm{PAR}+\mathrm{OH} \rightarrow \mathrm{XPAR}\end{array}$ & $\begin{array}{l}5.67 \times 10^{-11} \\
8.1 \times 10^{-13}\end{array}$ & $\begin{array}{l}\text { MCM v3.3.1 } \\
\text { CB6r }^{2}\end{array}$ \\
\hline ethyltoluenes & Treated as a OXYL + PAR & & \\
\hline tetramethylbenzenes & Treated as a TM123B + PAR & & \\
\hline
\end{tabular}

a) 1: (Yarwood et al., 2010), 2: (Jenkin et al., 2012) 


\section{Section S2. Model parameters in the absence of gas-wall partitioning.}

\section{S2.1. Near Explicit UNIPAR-GWP}

The UNIPAR model was coupled with the Master Chemical Mechanism (MCM v3.3.1) to explicitly treat SOA formation by using individual chemical properties (i.e., molecular weight, $\mathrm{O}: \mathrm{C}$ ratio, hydrogen bonding) of oxygenated products. The UNIPAR simulation was performed in the box model platform by using the Dynamically Simple Model of Atmospheric Chemical Complexity (DSMACC)(Emmerson and Evans, 2009) platform integrated with the Kinetic PreProcessor (KPP)(Damian et al., 2002). The oxidation products from the MCM mechanisms were explicitly integrated with the UNIPAR model.

To assess the impact if gas-wall partitioning (GWP) on SOA formation, UNIPAR model was coupled with GWP model (UNIPAR-GWP). In UNIPAR-GWP, both gas-particle partitioning and GWP were kinetically treated by using the absorption rate constants (kon) and desorption rate constants (koff) of organic species $i$, in the or, in, and $w$ phases. The SOA growth via in-particle chemistry was also kinetically treated as the second-order dimerization reaction of condensed organics with aerosol phase reaction rate constants $\left(k_{o, i}\right.$ for organic phase and $k_{A C, i}$ for the inorganic phase).(Odian, 2004) The kinetic mechanisms associate with the oxidation product $i$ were listed as:

1) Gas phase oxidation (MCM v3.3.1)

40 $I_{g}+\mathrm{OH} \stackrel{k_{O H, i}}{\longrightarrow} I_{g}^{\prime}$

2) Gas-particle partitioning (into the organic phase)

$$
\begin{aligned}
& I_{g} \stackrel{\text { kon }_{o r, i}}{\longrightarrow} I_{o r} \\
& I_{o r} \stackrel{\text { kof } f_{o r, i}}{\longrightarrow} I_{g}
\end{aligned}
$$

3) Gas-particle partitioning (into the inorganic phase)

$$
\begin{aligned}
& I_{g} \stackrel{\text { kon }_{\text {in }, i}}{\longrightarrow} I_{i n} \\
& I_{i n} \stackrel{\text { koff } f_{i n, i}}{\longrightarrow} I_{g}
\end{aligned}
$$

4) Gas-wall partitioning (GWP)

$$
\begin{aligned}
& I_{g} \stackrel{\text { kon }_{w, i}}{\longrightarrow} I_{w} \\
& I_{w} \stackrel{k o f f_{w, i}}{\longrightarrow} I_{g}
\end{aligned}
$$

5) In-particle chemistry (organic phase)

$$
2^{\text {nd }} \text { order reaction }
$$

6) In-particle chemistry (inorganic phase)

$$
2^{\text {nd }} \text { order reaction }
$$

In this study, reversibility of oligomerization was not considered. Figure S2 illustrates the simple structure of 


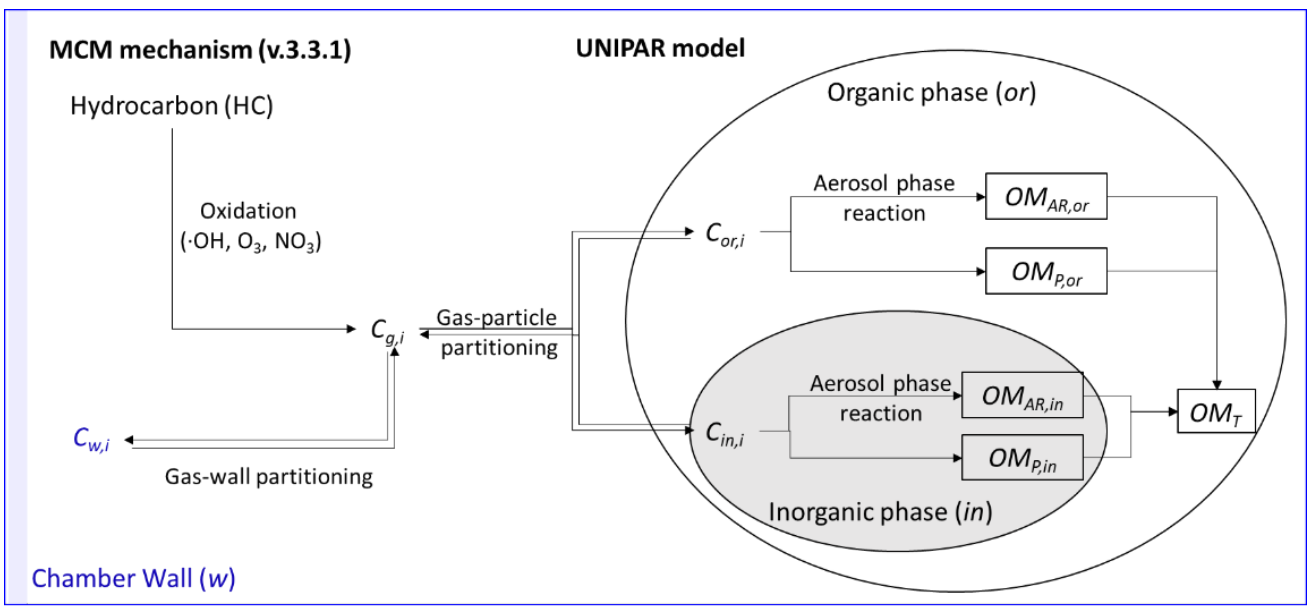

Figure S2. The structure of the UNIPAR-GWP model, simulated to predict the impact of GWP on aromatic SOA formation. $C$ denotes the concentration of the organic compound ( $i$ ) in gas phase (g), organic phase (or), inorganic phase (in), and chamber wall phase (w). $C_{g, i}$ is simulated using the gas kinetic mechanisms (MCM v3.3.1). The gasphase reactions, multiphase partitioning processes, and aerosol-phase reactions to form the SOA mass are integrated into a chemical solver under the Dynamically Simple Model of the Atmospheric Chemical Complexity (DSMACC) platform.

The chemical properties were explicitly treated for partitioning processes. The physicochemical parameters of oxygenated products resulting from the MCM mechanism were obtained from individual species. For GWP, the physicochemical parameters (hydrogen bond donor $\left(H_{d, i}\right)$, hydrogen bond acceptor $\left(H_{a, i}\right)$, dipolarity/polarizability $\left(S_{i}\right)$, and polarizability $\left(P_{i}\right)$ ) of $i$ were obtained from PaDEL-descriptor (Yap, 2011) and applied to calculate the GWP parameter (Han and Jang, 2020). The gas-wall partitioning coefficient $\left(K_{w}\right)$ and absorption rate constant $\left(k_{k o n} n_{w, i}\right)$ are two important GWP parameters which can determine the deposition of organic vapor to the chamber wall. $K_{w}$ is a unitless partitioning coefficient derived from the traditional partitioning coefficient by multiplying organic matter absorbed on the chamber wall $\left(O M_{\text {wall }}\right)$ (Han and Jang, 2020;Krechmer et al., 2016):

$$
K_{w, i}=\frac{7.501 R T O M_{w a l l}}{10^{9} M W_{O M} \gamma_{w, i} p_{L, i}^{\circ}}
$$

where $M W_{O M}$ is the molecular weight of $O M_{w a l l}$ and $\gamma_{w, i}$ is the activity coefficient of $i$ in the wall phase. R (8.314 J $\mathrm{mol}^{-1} \mathrm{~K}^{-1}$ ) is the ideal gas constant, and $\mathrm{T}(\mathrm{K})$ is the temperature. $p_{L, i}^{\circ}$ denotes the vapor pressure of $i$. The absorption rate constant $\left(\right.$ kon $\left._{w, i}\right)$ of $i$ to the wall is expressed as a fractional loss rate with the accommodation coefficient $\left(\alpha_{\text {wall }, i}\right)($ McMurry and Grosjean, 1985) of $i$ to the organic matter on the chamber wall:

$$
\operatorname{kon}_{w, i}=\left(\frac{A}{V}\right) \frac{\alpha_{w a l l, i} \bar{v}_{i} / 4}{1+\frac{\pi \alpha_{w a l l, i} \bar{v}_{i}}{8 \sqrt{K_{e} D}}}
$$

where $D\left(1.0 \times 10^{-6} \mathrm{~m}^{2} \mathrm{~s}^{-1}\right)$ and $K_{e}\left(0.12 \mathrm{~s}^{-1}\right)$ are the diffusion coefficient and the coefficient of eddy diffusion, respectively. $\bar{v}_{i}$ is the gas molecules' mean thermal speed of $i$. A is the surface area and $\mathrm{V}$ is the volume of the chamber. The important parameters, activity coefficient of $i$ to the wall $\left(\gamma_{w, i}\right)$ to calculate $K_{w}$ and accommodation coefficient $\left(\alpha_{\text {wall }, i}\right)$ to calculate $k_{\text {on }}$, were estimated by applying a quantitative structure activity relationship (QSAR) employing organic vapors' physicochemical properties. QSAR models are semiempirically determined by using the experimental data that measured time series gas-phase concentrations of SVOCs in the UF-APHOR chamber to predict $\gamma_{w, i}$ and $\alpha_{\text {wall, } i}$ :

$$
\begin{gathered}
\ln \left(\gamma_{w, i}\right)=2.25 e^{0.0007 R H} H_{d, i}+0.79 e^{0.022 R H} H_{a, i}+0.13 e^{0.0025 R H} P_{i}-6.54 e^{0.0047 R H} \\
\ln \left(\alpha_{\text {wall }, i}\right)=-0.33 H_{d, i}-3.00 H_{a, i}-0.05 P_{i}-0.61 S_{i}-9.69
\end{gathered}
$$


where $H_{d, i}, H_{a, i}, S_{i}$, and $P_{i}$ indicate the hydrogen bond donor, hydrogen bond acceptor, dipolarity/polarizability, and polarizability, respectively (Abraham and McGowan, 1987;Abraham et al., 1991;Platts et al., 1999).

The UNIPAR-GWP model was limited to simulate individual compounds of data due to the complexity of mechanism, and thus it was applied to correct the SOA parameters for GWP bias. To improve the SOA parameters, aerosol phase reaction rate constant $\left(k_{o, i}\right)$ was semiempirically determined by including the GWP mechanism to predict the SOA data generated from the UF-APHOR chamber. 


\section{S2.2. Simulation of aromatic SOA using UNIPAR-CB6r3}

The chamber experiments were conducted under various seed conditions, such as NS (non-seed), SA (sulfuric acid seeded), wAS (wet ammonium sulfate seeded), and $\mathrm{SO}_{2}$, to test $\mathrm{SOA}$ parameters and evaluate the feasibility of the UNIPAR-CB6r3 model. Experimental conditions for each chamber experiment are summarized in the Table S2.

Table S2. Experimental conditions of the chamber studies.

\begin{tabular}{|c|c|c|c|c|c|c|c|c|c|c|}
\hline \multirow[b]{2}{*}{ Precursor } & \multirow[b]{2}{*}{ Date $^{a}$} & \multicolumn{4}{|c|}{ Initial condition } & \multirow[b]{2}{*}{$\begin{array}{c}\mathrm{OM}_{0}^{\mathrm{d}} \\
\left(\mu \mathrm{g} \mathrm{m}^{-3}\right)\end{array}$} & \multirow[b]{2}{*}{$\begin{array}{l}Y_{S O A}{ }^{\mathrm{e}} \\
(\%)\end{array}$} & \multirow[b]{2}{*}{$\begin{array}{l}\mathrm{RH}^{\mathrm{f}} \\
(\%)\end{array}$} & \multirow[b]{2}{*}{$\begin{array}{l}\text { Temp. } \\
\text { (K) }\end{array}$} & \multirow[b]{2}{*}{ Figure } \\
\hline & & $\begin{array}{c}\mathrm{HC} \\
(\mathrm{ppb})\end{array}$ & $\begin{array}{c}\mathrm{NO}_{x} \\
(\mathrm{HONO}) \\
(\mathrm{ppb})\end{array}$ & $\begin{array}{l}\text { Seeded aerosol } \\
\left(\mathrm{ppb} \text { or } \mu \mathrm{g} \mathrm{m}^{3}{ }^{3}\right)\end{array}$ & $\begin{array}{c}\mathrm{HC}^{\mathrm{NO} \mathrm{N}_{x}} \\
(\mathrm{ppbC} / \mathrm{ppb})\end{array}$ & & & & & \\
\hline \multirow{2}{*}{ Benzene } & $05 / 31 / 20 \mathrm{~W}$ & 515 & $680(125)$ & - & 4.2 & 5 & 3.8 & $37-99$ & 295-321 & $2, \mathrm{~S} 4(\mathrm{c})$ \\
\hline & $06 / 17 / 20 \mathrm{E}$ & 496 & $648(134)$ & SA (50) & 4.6 & 5 & 9.0 & $22-91$ & $291-320$ & 2 \\
\hline \multirow{3}{*}{ toluene } & $06 / 25 / 20 \mathrm{E}$ & 198 & $350(160)$ & - & 5.0 & 2 & 2.6 & $21-70$ & 296-321 & 2, S3(a), S4(a) \\
\hline & $02 / 23 / 2019 \mathrm{E}$ & 104 & $76(76)$ & wAHS (250) & 9.6 & 2 & 20.2 & $27-79$ & $293-318$ & $2, \mathrm{~S} 4(\mathrm{~b})$ \\
\hline & $02 / 23 / 2019 \mathrm{~W}$ & 120 & $65(65)$ & wAS (350) & 12.9 & 2 & 19.2 & $34-86$ & $294-315$ & $2, \mathrm{~S} 4(\mathrm{~b})$ \\
\hline \multirow{2}{*}{ ethylbenzene } & $12 / 10 / 17 \mathrm{E}^{\mathrm{b}}$ & 131 & $363(13)$ & $\mathrm{SO}_{2}(39)$ & 2.7 & 3 & 10.1 & $20-83$ & $271-298$ & 2 \\
\hline & $12 / 10 / 17 \mathrm{~W}^{\mathrm{b}}$ & 128 & $363(15)$ & - & 2.8 & 3 & 4.1 & $33-86$ & $272-295$ & 2 \\
\hline \multirow{2}{*}{ propylbenzene } & $03 / 28 / 18 E^{b}$ & 87 & $264(36)$ & $\mathrm{SO}_{2}(54)$ & 3.0 & 3 & 7.1 & $11-43$ & $285-312$ & $2, \mathrm{~S} 4(\mathrm{f})$ \\
\hline & $03 / 28 / 18 \mathrm{~W}^{\mathrm{b}}$ & 88 & $248(33)$ & - & 3.2 & 3 & 4.6 & $16-51$ & $285-312$ & $2, \mathrm{~S} 4(\mathrm{f})$ \\
\hline \multirow{2}{*}{ m-xylene } & $11 / 27 / 2018 \mathrm{E}$ & 114 & 272 & SA (80) & 3.4 & 2 & 6.0 & $31-90$ & $277-297$ & 2, S3(d), S4(e) \\
\hline & $11 / 27 / 2018 \mathrm{~W}$ & 117 & 274 & - & 3.4 & 2 & 2.0 & $51-93$ & $277-295$ & $2, \mathrm{~S} 4(\mathrm{e})$ \\
\hline \multirow{2}{*}{ o-xylene } & $10 / 28 / 2018 \mathrm{E}$ & 131 & 289 & SA (70) & 3.6 & 2 & 6.6 & $14-66$ & $281-310$ & $2, \mathrm{~S} 3(\mathrm{~b}), \mathrm{S} 4(\mathrm{~d})$ \\
\hline & $10 / 28 / 2018 \mathrm{~W}$ & 128 & 294 & wAS (80) & 3.5 & 2 & 4.0 & $36-93$ & $282-310$ & $2, \mathrm{~S} 4(\mathrm{~d})$ \\
\hline \multirow{2}{*}{ p-xylene } & 01/21/2019 E & 121 & 86 & SA (70) & 11.3 & 2 & 11.6 & $15-70$ & 271-299 & 2 \\
\hline & $01 / 21 / 2019 \mathrm{~W}$ & 119 & 79 & - & 12.1 & 2 & 3.1 & $26-74$ & 272-299 & 2 \\
\hline \multirow{2}{*}{ 1,2,3TMB } & $9 / 25 / 2018 \mathrm{E}$ & 148 & 353 & SA (50) & 3.8 & 2 & 5.4 & $12-39$ & 296-322 & 2 \\
\hline & 9/25/2018 W & 141 & 335 & - & 3.8 & 2 & 1.0 & $16-41$ & 296-321 & 2 \\
\hline \multirow{2}{*}{$1,2,4 \mathrm{TMB}$} & $9 / 8 / 2018 \mathrm{E}$ & 115 & 275 & SA (70) & 3.8 & 2 & 1.9 & $13-44$ & 294-321 & $2, \mathrm{~S} 3(\mathrm{e}), \mathrm{S} 4(\mathrm{~h})$ \\
\hline & $9 / 8 / 2018 \mathrm{~W}$ & 115 & 269 & - & 3.8 & 2 & 0.9 & $19-50$ & 295-319 & 2, S4(h) \\
\hline \multirow{2}{*}{ 1.3.5TMB } & 9/10/2019 E & 210 & 600 & - & 3.2 & 5 & 1.1 & $13-40$ & 296-322 & $2, \mathrm{~S} 4(\mathrm{~g})$ \\
\hline & 9/10/2019 W & 211 & 617 & SA (50) & 3.1 & 5 & 3.4 & $23-50$ & $297-319$ & 2, S4(g) \\
\hline
\end{tabular}

a. "E" or "W" that follows the experiment date represents the east or west chamber for the UF APHOR, respectively.

b. The SOA data obtained from (Zhou et al., 2019).

c. "SA", "wAS", or "wAHS" denotes that the experiment with sulfuric-acid aerosol, wet ammonium-sulfate aerosol, or wet ammonium-hydrogen sulfate aerosol is directly injected to the chamber, respectively. $\mathrm{SO}_{2}$ (in the unit of $\mathrm{ppb}$ ) was injected into the chamber to generate sulfuric acidic seeds under the sun light.

d. The pre-existing organic matter $\left(\mathrm{OM}_{0}\right)$ is determined based on the measured organic matter in the chamber before experiment and applied to the simulation for the initial condition.

e. SOA yield is estimated using $\mathrm{Y}_{\mathrm{SOA}}=\Delta \mathrm{OM} \mathrm{M} / \Delta \mathrm{HC}$. Yield in the table was estimated when SOA mass reached to the maximum over the course of the experiments. f. The accuracy of relative humidity $(\mathrm{RH})$ is $5 \%$. The accuracy of temperature is $0.5 \mathrm{~K}$. 
The time profiles of the simulated concentration of $\mathrm{NO}, \mathrm{NO}_{2}, \mathrm{O}_{3}$, and aromatic $\mathrm{HC}$ with $\mathrm{CB} 6 \mathrm{r} 3$ mechanism under the experimental conditions (Table S2) are illustrated in Fig. S3. The simulated aromatic SOA mass with UNIPAR-CB6r3 model under the experimental conditions (Table S2) is shown in Fig. S4.
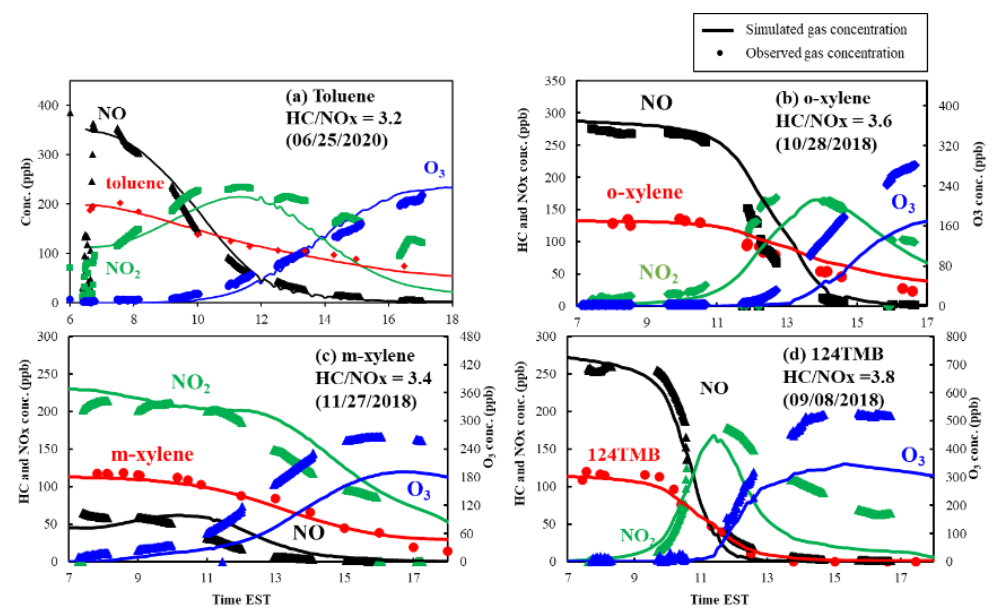

Figure S3. Observed (symbol) and simulated (line) concentration of $\mathrm{NO}, \mathrm{NO}_{2}, \mathrm{O}_{3}$, and $\mathrm{HC}$ for the photooxidation of individual aromatic HCs. The environmental conditions of the chamber experiment are described in Table S2.
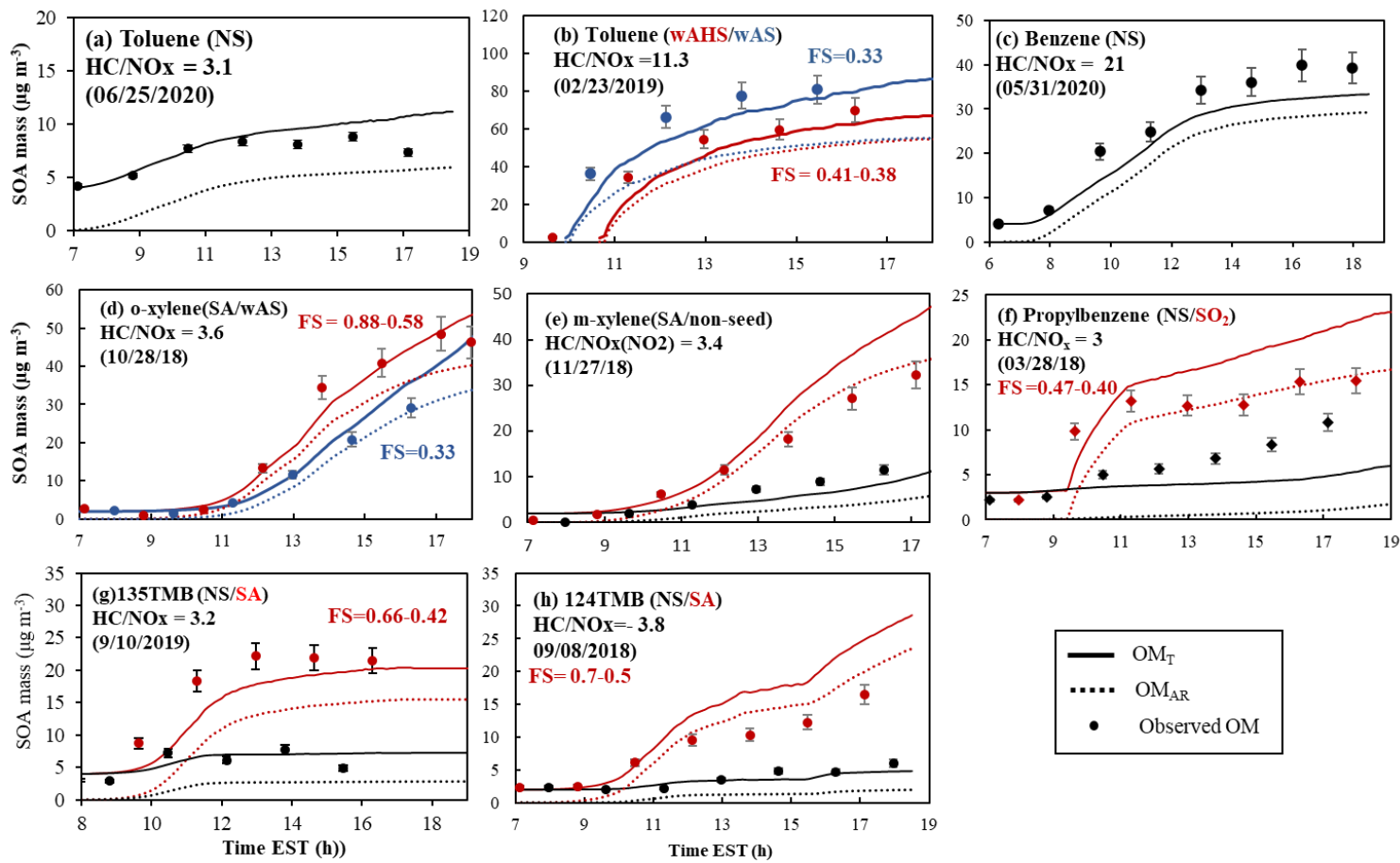

Figure S4. Observed (plot) and simulated (line) SOA mass in the chamber studies of aromatic HCs. The simulated $\mathrm{OM}_{\mathrm{T}}$ (solid line) and $\mathrm{OM}_{\mathrm{AR}}$ (dotted line) are illustrated. Particle loss of experimental data onto the chamber wall was corrected. The ranges of FS are presented for experiment under the acidic condition to indicate aerosol acidity over the course of the experiment. The error (9\%) associated with SOA mass was estimated with the instrumental error originating from the OC/EC analyzer.

Overall, the simulated concentrations of aromatic $\mathrm{SOA}, \mathrm{NO}, \mathrm{NO}_{2}, \mathrm{O}_{3}$, and $\mathrm{HC}$ with UNIPAR-CB6r3 agrees with the observed values in the chamber studies. 


\section{Section S3. Sunlight intensities}

The sunlight intensity illustrated in Fig. S5 (a) was measured on 06/19/2015 in the UF-APHOR and applied as a reference sunlight intensity for the sensitivity and uncertainty tests. For the simulation of chamber experiment, the measured sunlight intensity was used. To illustrate the difference in sunlight intensities due to the seasonal variation, the measured sunlight intensities in March and December were illustrated in Figure S5 (b).

(a) Reference sunlight intensity $(6 / 19 / 2015)$

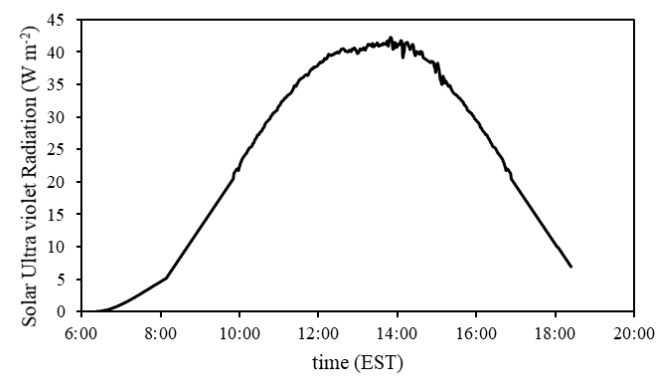

(b) Sunlight intensity during the experiment

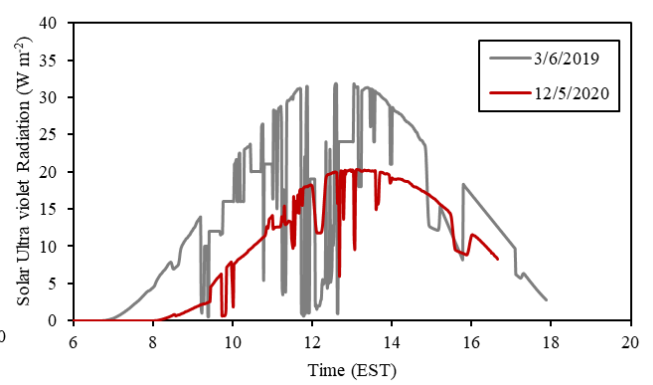

Figure S5. Time profile of sunlight intensity measured by total ultra-violet radiation (TUVR) in the UF-APHOR on (a) $06 / 19 / 2015$ for the reference sunlight intensity, and that on (b) 3/6/2019 and 12/5/2020 during the experiments. 


\section{Section S4. SOA simulation using CMAQ-AE7 aerosol module}

To compare the SOA simulation results between UNIPAR-CB6r3 and CMAQ-AE7, 2 gasoline SOA data generated in UF-APHOR in the absence of wet inorganic seed were simulated with both models. In CMAQ-AE7, the first order oligomerization reaction of organic species is included in gas mechanisms with the rate constant as $9.5 \times 10^{-6}$ molecules $\mathrm{s}^{-1} \mathrm{~cm}^{-3}$, while UNIPAR-CB6r3 treats the oligomerization as the second order self-dimerization reaction. In Fig. S6, the SOA simulation with CMAQ-AE7 is compared to the SOA data generated from the photooxidation of gasoline vapor. The simulated gasoline SOA using UNIPAR-CB6r3 is shown in Fig. 4 in the manuscript.
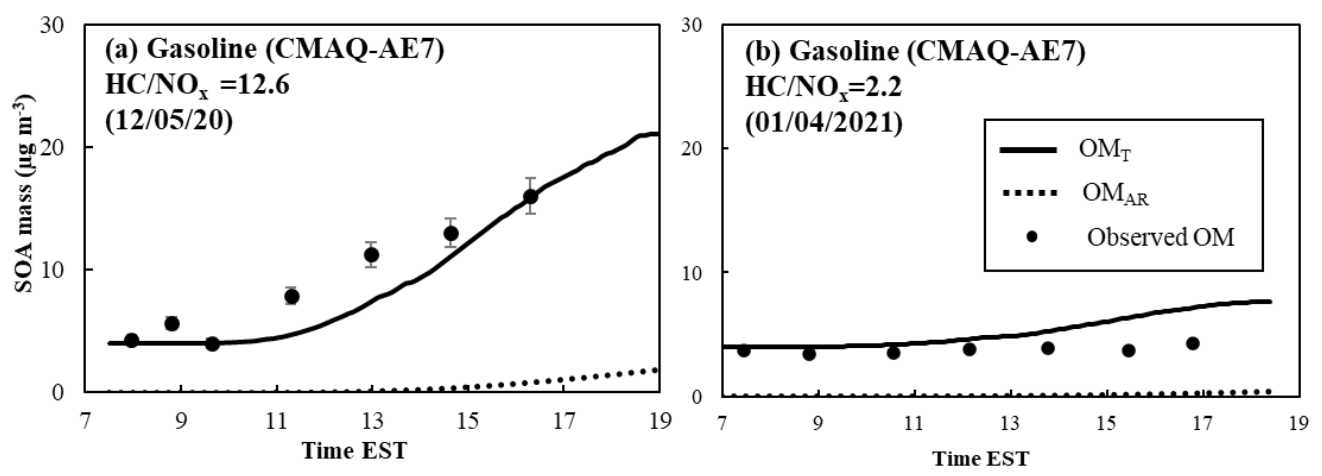

Figure S6. Simulation of gasoline SOA mass by using the CMAQ-AE7 module against SOA data generated without inorganic seed in the UF-APHOR chamber (Table 1). 
Section S5. The list of the acronyms or abbreviations

Table S3. The list of the acronyms and abbreviations.

\begin{tabular}{|c|c|}
\hline $\begin{array}{l}\text { Acronyms or } \\
\text { abbreviation }\end{array}$ & Definition \\
\hline GWP & Gas-Wall Partitioning \\
\hline $\mathrm{HC}$ & Hydrocarbon \\
\hline QSAR & Quantitative Structure Activity Relationship \\
\hline RH & Relative Humidity \\
\hline $\mathrm{OC}$ & Organic carbon \\
\hline$\Delta \mathrm{HC}$ & The consumption of hydrocarbons \\
\hline$\left[\mathrm{RO}_{2}\right]$ & The concentration of $\mathrm{RO}_{2}$ \\
\hline$\left[\mathrm{HO}_{2}\right]$ & The concentration of $\mathrm{HO}_{2}$ \\
\hline$\alpha_{i}$ & The stoichiometric coefficient of the lumping species $i$ \\
\hline $\mathrm{OM}_{\mathrm{T}}$ & Total SOA mass \\
\hline $\mathrm{OM}_{\mathrm{P}}$ & The SOA mass generated via gas-particle partitioning \\
\hline $\mathrm{OM}_{\mathrm{AR}}$ & The SOA mass generated via heterogeneous reactions in organic and inorganic phases \\
\hline$p_{L, i}^{\circ}$ & Vapor pressure of the lumping species $i(\mathrm{mmHg})$ \\
\hline$M W_{i}$ & Molecular weight of the lumping species $i(\mathrm{~g} / \mathrm{mol})$ \\
\hline$O: C_{i}$ & Oxygen to carbon ratio of the lumping species $i$ \\
\hline$H B_{i}$ & Hydrogen bonding of the lumping species $i$ \\
\hline$R_{i}$ & Reactivity scale of the lumping species $i$ in the aerosol phase \\
\hline$C_{g, i}$ & The gas concentration of lumping species $i$ \\
\hline$C_{\text {or }, i}$ & The concentration of lumping species $i$ partition onto the organic phase \\
\hline$C_{i n, i}$ & The concentration of lumping species $i$ partition onto the inorganic phase \\
\hline$K_{\text {or }, i}$ & The partitioning coefficient of $i$ into the organic phase \\
\hline$K_{i n, i}$ & The partitioning coefficient of $i$ into the inorganic phase \\
\hline$M W_{\text {or }}$ & The averaged molecular weight of $\mathrm{OM}_{\mathrm{T}}\left(\mathrm{g} \mathrm{mol}^{-1}\right)$ \\
\hline $\mathrm{R}$ & The ideal gas constant $\left(8.314 \mathrm{~J} \mathrm{~mol}^{-1} \mathrm{~K}^{-1}\right)$ \\
\hline $\mathrm{T}$ & Temperature $(\mathrm{K})$ \\
\hline$M W_{\text {in }}$ & The averaged molecular weight of inorganic aerosol $\left(\mathrm{g} \mathrm{mol}^{-1}\right)$ \\
\hline$\gamma_{o r, i}$ & The activity coefficient of $i$ in organic phase \\
\hline$\gamma_{i n, i}$ & The activity coefficient of $i$ in inorganic phase \\
\hline FS & Fractional sulfate \\
\hline SA & Sulfuric acid \\
\hline AS & Ammonium sulfate \\
\hline$C_{o r, i}^{\prime}$ & The concentration of $i$ in the organic aerosol phase $\left(\mathrm{mol} \mathrm{L}^{-1}\right)$ \\
\hline$C_{i n, i}^{\prime}$ & The concentration of $i$ in the inorganic aerosol phase $\left(\mathrm{mol} \mathrm{L}^{-1}\right)$ \\
\hline$k_{A C, i}$ & The reaction rate constant in the aqueous phase \\
\hline$k_{o, i}$ & The reaction rate constant in the organic phase \\
\hline$p K_{B H_{i}^{+}}$ & The protonation equilibrium constant \\
\hline $\mathrm{X}$ & The excess acidity \\
\hline$a_{w}$ & The water activity \\
\hline$\left[\mathrm{H}^{+}\right]$ & The proton concentration \\
\hline$C_{T, i}$ & The total concentration of $i$ \\
\hline$C_{g, i}^{*}$ & the effective saturation concentration of $i$ \\
\hline$O M_{0}$ & The pre-existing OM concentration $\left(\mathrm{mol} \mathrm{m}^{-3}\right)$ \\
\hline $\mathrm{OM}$ & The organic matter \\
\hline$M W_{\text {oli }, i}$ & The molecular weight of the dimer $\left(\mathrm{g} \mathrm{mol}^{-1}\right)$. \\
\hline$k^{\prime} n_{w}$ & The absorption rate constant of $i$ into the chamber wall \\
\hline$k o f f_{w}$ & The desorption rate constant of $i$ from the chamber wall \\
\hline LLPS & Liquid-liquid phase separation \\
\hline NS & No-seeded \\
\hline
\end{tabular}




\begin{tabular}{|c|l|}
\hline wAHS & Wet ammonium bisulfate \\
\hline $\mathrm{dAS}$ & Dry ammonium sulfate \\
\hline$C_{S O A}$ & The aromatic SOA mass in the absence of GWP bias $\left(\mu \mathrm{g} \mathrm{m}^{-3}\right)$ \\
\hline$C_{S O A, \text { wall }}$ & The aromatic SOA mass in the presence of GWP bias $\left(\mu \mathrm{g} \mathrm{m}^{-3}\right)$ \\
\hline ERH & Efflorescence relative humidity \\
\hline DRH & Deliquescence relative humidity \\
\hline
\end{tabular}




\section{References}

Abraham, M., and McGowan, J.: The use of characteristic volumes to measure cavity terms in reversed phase liquid-chromatography, Chromatographia, 23, 243-246, 10.1007/BF02311772, 1987.

Abraham, M., Whiting, G., Doherty, R., and Shuely, W.: Hydrogen-bonding. 16. A new solute solvation parameter, Pi-2(H), from Gas-Chromatographic data, Journal of Chromatography, 587, 213-228, 10.1016/0021-9673(91)85158-C, 1991.

155 Damian, V., Sandu, A., Damian, M., Potra, F., and Carmichael, G. R.: The kinetic preprocessor KPP-a software environment for solving chemical kinetics, Computers \& Chemical Engineering, 26, 1567-1579, 2002.

Emmerson, K., and Evans, M.: Comparison of tropospheric gas-phase chemistry schemes for use within global models, Atmospheric Chemistry \& Physics, 9, 2009.

160 Han, S., and Jang, M.: Simulating the impact of gas-wall partitioning on SOA formation using the explicit gas mechanism integrated with aqueous reactions containing electrolytes, Science of The Total Environment, 748, 141360, 2020.

Jenkin, M., Wyche, K., Evans, C., Carr, T., Monks, P., Alfarra, M., Barley, M., McFiggans, G., Young, J., and Rickard, A.: Development and chamber evaluation of the MCM v3.2 degradation scheme for betacaryophyllene, Atmospheric Chemistry and Physics, 12, 5275-5308, 10.5194/acp-12-5275-2012, 2012.

Krechmer, J., Pagonis, D., Ziemann, P., and Jimenez, J.: Quantification of Gas-Wall Partitioning in Teflon Environmental Chambers Using Rapid Bursts of Low-Volatility Oxidized Species Generated in Situ, Environmental Science \& Technology, 50, 5757-5765, 10.1021/acs.est.6b00606, 2016.

McMurry, P., and Grosjean, D.: Gas and aerosol wall losses in Teflon film smog chambers, Environmental Science \& Technology, 19, 1176-1182, 10.1021/es00142a006, 1985.

Odian, G.: Principles of Polymerization, 4th ed., A JOHN WILEY \& SONS, INC., New York, 2004.

Platts, J., Butina, D., Abraham, M., and Hersey, A.: Estimation of molecular linear free energy relation descriptors using a group contribution approach, Journal of Chemical Information and Computer Sciences, 39, 835-845, 10.1021/ci980339t, 1999.

175 Yap, C.: PaDEL-Descriptor: An Open Source Software to Calculate Molecular Descriptors and Fingerprints, Journal of Computational Chemistry, 32, 1466-1474, 10.1002/jcc.21707, 2011.

Yarwood, G., Jung, J., Whitten, G. Z., Heo, G., Mellberg, J., and Estes, M.: Updates to the Carbon Bond mechanism for version 6 (CB6), 9th Annual CMAS Conference, Chapel Hill, NC, 2010, 11-13,

Zhou, C., Jang, M., and Yu, Z.: Simulation of SOA formation from the photooxidation of monoalkylbenzenes in the presence of aqueous aerosols containing electrolytes under various $\mathrm{NO} \times$ levels, Atmospheric Chemistry and Physics, 19, 5719-5735, 2019. 